\title{
Re-purposive Use of Drugs in COVID-19: A Wake-up Call
}

\author{
MA RAHIM $^{\mathrm{a}}$, M MOSTAFI ${ }^{\mathrm{b}}$
}

Due to unavailability of effective therapeutic agents and the anticipated time lag between the speed of spread of the novel corona virus (nCoV) (later re-named as severe acute respiratory syndrome-coronavirus-2, SARS-CoV-2) and the discovery of effective vaccines against corona virus disease-19 (COVID-19), various available anti-viral, anti-bacterial and anti-malarial drugs have been re-purposively used by physicians all over the world, with the hope to cut-down the huge human death-tolls and sufferings. Available evidences did not convincingly advocate their clinical use, though some favorable reports ${ }^{1}$ exist amid the clinical context of COVID-19, but few of these evidences are retracted.

Ivermectin, a broad-spectrum endo/ecto-parasiticide has been shown to have a wide-spectrum anti-viral activity against many ribonucleic acid (RNA) viruses and few deoxyribonucleic acid (DNA) viruses, but the in vivo benefit of ivermectin was proven only against the West Nile virus and Newcastle disease virus. ${ }^{2-4}$ Ivermectin reduces serum concentrations of non-structural protein 1 (NS-1) in dengue but neither reduces viraemia nor has clinical benefit ${ }^{5}$, as is true for chikungunya and Zika. Because of the recent in vitro observation of ivermectin's inhibitory effect against replication of SARS-CoV-2 in first 48 hours and the in vitro and possible clinical utility of hydroxychloroquine and ivermectin, there arise the scope for clinical trials and then re-purposive use of ivermectin in COVID-19. ${ }^{6-9}$ Caution is sought by researchers regarding clinical use of ivermectin in COVID-19 and virtually, the concentration at which level in vitro anti-SARS-CoV-2 activity of ivermectin was discovered, is not attainable in conventional dosing regimens. ${ }^{10}$

News on electronic and print media ${ }^{11,12}$ in Bangladesh, describing the success of ivermectin and doxycycline combination in COVID-19, has made people very much enthusiastic of being treated by these drugs, in the absence of any acceptable remedy, till date. Availability of these low-cost drugs in medicine shops, in the absence of an effective monitoring system on medicine dispensing (without prescription), have made this happen in Bangladesh. Reverse-transcriptase polymerase chain reaction (RT-PCR)-negativity within four days of starting therapy sounds miracle to general people, seemingly such to some practicing physicians and village doctors, who allegedly have started prescribing these combinations. But, the asymptomatic patients or those with mild symptoms do not merit any specific medication. ${ }^{13}$ As many patients were asymptomatic ${ }^{14}$, it was uncertain for how many days they were carrying the virus. So, such a correlation between the start of treatment and becoming RT-PCRnegative in asymptomatic patients remains a question of debate. If these patients could be compared with a similar cohort of COVID-19 patients on standard care or without any drug intervention, then it would sound a more logical claim; however, the authors have correctly recommended for further trials.

Another paper ${ }^{15}$ in this COVID-Supplement issue of the Journal of Bangladesh College of Physicians and Surgeons compared utility of ivermectin plus doxycycline and hydroxychloroquine plus azythromycine on viral clearance. In this study, outcomes of the two groups were evaluated in different time frames, on day 5 and day 11 respectively for the two aforementioned groups and that makes the comparisons disputed. The role of follow-up RT-PCR remains controversial; viral remnants in the respiratory tract may react positively and do not necessarily mean persistent infection, reinfection or infectivity. ${ }^{16}$ So, such reports require extreme caution during interpretation. Furthermore, the observations, that many severe and critically ill COVID-19 patients admitted in COVIDdedicated hospitals in Bangladesh had history of taking such medications at symptom onset, may raise question towards the beneficial effects of such drugs.

According to a published news ${ }^{12}$, a clinical trial is onway to compare the therapeutic effects of ivermectin, ivermaectin plus doxycycline and placebo; the findings of this placebo-controlled trial including COVID-19 patients with different grades of severity and evaluating parameters like symptom relief, viral clearance, 
requirement of oxygen and other supports, as well as drug adverse effects, are expected to be better evidences. Again, this trial is planned to recruit a small number of patients; findings from such a small study participants is likely to raise questions towards reliability.

Meanwhile, Bangladesh National Guidelines on Clinical Management of Coronavirus Disease-2019 reviewed its medication list. ${ }^{13}$ People are using many drugs without any definite proof of benefit. So, high-powered, randomized, double-blind, placebo-controlled trials recruiting larger numbers of COVID-19 patients with different severity groups, is expected to provide a reliable statement in this issue. Till then, it would remain as a wake-up call towards the treating physicians to remain very much cautious in re-purposive use of drugs against COVID-19 and "do no harm" to the patients.

(J Bangladesh Coll Phys Surg 2020; 38: 3-4) DOI: https://doi.org/10.3329/jbcps.v38i0.47438

a. Dr. Muhammad Abdur Rahim, Associate Professor, Department of Nephrology, BIRDEM General Hospital, Dhaka, Bangladesh.

E-mail:muradrahim23@yahoo.com

b. Prof. Brig. Gen (Retd.) Mamun Mostafi, Professor and Head, Department of Nephrology, Gonoshahthaya Samajvittik Medical College and Gonoshasthaya Nagar Hospital, Dhaka, Bangladesh. E-mail:mamunmostafi@yahoo.com

\section{References:}

1. Rajter JC, Sherman M, Fatteh N, Vogel F, Sacks J, Rajter J. ICON (Ivermectin in COvid Nineteen) study: Use of Ivermectin is Associated with Lower Mortality in Hospitalized Patients with COVID19. medRxiv. The Preprint Sarver for Health Sciences. Posted, June 10, 2020. (Accessed June 30, 2020)

2. Sharun K, Dhama K, Patel SK, Pathak M, Tiwari R, Singh $\mathrm{BR}$, et al. Ivermectin, a new candidate therapeutic against SARS CoV 2/COVID 19. Ann Clin Microbiol Antimicrob 2020;19:23.

3. Nguyen C, Burton T, Kuklinski W, Gray M, Foy BD. Ivermectin for the control of West Nile virus transmission. New Horizons Transl Med 2015;2(4):127.

4. Azeem S, Ashraf M, Rasheed MA, Anjum AA, Hameed R. Evaluation of cytotoxicity and antiviral activity of ivermectin against Newcastle disease virus. Pak J Pharm Sci 2015;28(2):597-602.
5. Yamasmith E, Avirutnan P, Mairiang D, Tanrumluk S, Suputtamongkol Y, Saleh-arong FA, et al. Efficacy and safety of ivermectin against dengue infection: a phase III, randomized, double-blind, placebo-controlled trial. In: The 34th Annual Meeting the Royal College of Physicians of Thailand. Internal Medicine and One Health, Chonburi, Thailand. 2018.

6. Caly L, Drucea JD, Cattona MG, Jansb DA, Kylie M. Wagstaffb KM, et al. The FDA-approved drug ivermectin inhibits the replication of SARS-CoV-2 in vitro. Antiviral Research 2020;178:104787.

7. Patr A, Fabbrocini G. Hydroxychloroquine and ivermectin: A synergistic combination for COVID-19 chemoprophylaxis and treatment? J Am Acad Dermatol June 2020;e221.

8. Choudhary R, Sharma AK. Potential use of hydroxychloroquine, ivermectin and azithromycin drugs in fighting COVID-19: trends, scope and relevance. New Microbe and New Infect 2020; 35: 100684.

9. US National Library of Medicine. Hydroxychloroquine and Ivermectin for the Treatment of COVID-19 Infection. ClinicalTrials.gov Identifier: NCT04391127. First Posted May 18, 2020. Last Updated June 12, 2020. (Accessed June 27, 2020)

10. Momekov G, Momekova D. Ivermectin as a potential COVID-19 treatment from the pharmacokinetic point of view: antiviral levels are not likely attainable with known dosing regimens, Biotechnology \& Biotechnological Equipment 2020; 34 (1):469-474.

11. UNB News. Covid-19: BMCH physician reports 'amazing results' using ivermectin, doxycycline. Published, June 6, 2020, 06:21 PM. Updated, June 7, 2020, 10:35 AM. (Accessed June 27, 2020).

12. Sujan MA. Use of Ivermectin: Hope held out, caution called for. The Daily Star. 12:00 AM, June 14, 2020 / Last Modified: 08:43 AM, June 14, 2020. (Accessed June 27, 2020)

13. Disease Control Division. Directorate General of Health Services. Ministry of Health \& Family Welfare. Government of the People's Republic of Bangladesh. National Guidelines on Clinical Management of Coronavirus Disease 2019 (COVID-19). Version 7.0. Published, 28 May 2020.

14. Alama MT, Murshed R, Bhiuyan E, Saber S, Alam RF, Robin RC. A Case Series of 100 COVID-19 Positive Patients Treated with Combination of Ivermectin and Doxycycline. J Bangladesh Coll Phys Surg 2020; 38 (Suppln.): 10-15.

15. Rahman MA, Iqbal SA, Islam MA, Niaz MK, Hussaine T, Siddiquee TH. Comparison of Viral Clearance between Ivermectin with Doxycycline and Hydroxychloroquine with Azithromycin in COVID-19 Patients. J Bangladesh Coll Phys Surg 2020; 38 (Suppln.): 5-9.

16. Lan L, Xu D, Ye G. Positive RT-PCR Test Results in Patients Recovered From COVID-19. JAMA 2020;323(15): 1502-1503. 